\title{
Reliability Analysis of 2D Steel Frame
}

\author{
S.J. Avinash, Dr.J.K. Dattatreya and Dr.V. Devaraj
}

\begin{abstract}
A two dimensional frame has been designed according to IS 800-2007 and are subjected to dead load, live load and earthquake load combination. In the present study reliability assessment of structural safety is studied. The uncertainties in geometry, loads and strength are accounted. The performance function for strength is studied using Hasofer Lind method. A MATLAB program has been developed for computing the reliability index for beams and columns. System reliability has been performed on the structure to find the reliability index of the system.
\end{abstract}

Keywords--- Reliability Analysis, Probability of Failure, Hasofer Lind Method, Reliability Index, System Reliability.

\section{INTRODUCTION}

$\mathrm{S}_{\mathrm{in}}^{\mathrm{T}}$ TRUCTURAL reliability analysis for systems plays an important role in the analysis and design of structures. The main purpose of structural reliability analysis is to evaluate the structural probability of failure. The probability of structural failure, takes into account the uncertainties associated with loads, geometry and resistance. Reliability assessment techniques help to develop safe designs and identify critical limit states. Structural reliability analysis results numerical measure of structural safety, given in terms of a failure probability or probability of safety.

\section{A. Reliability Analysis}

The failure of limit state performance is expressed as $\mathrm{P}_{\mathrm{f}}$, and the reliability as $\mathrm{R}$ follows the relation:

\section{Probability of safety (Reliability) $=1-\mathrm{P}_{\mathrm{f}}(1)$}

According to IS 800:2007 the tension member has two modes of failure i.e:

i. Failure by Yielding

ii. Failure by Rupture

$$
\begin{aligned}
& \mathrm{G}(\mathrm{R}, \mathrm{S}) \leq 0 \\
& \mathrm{P}_{\mathrm{f}}=\mathrm{P}[\mathrm{G}(\mathrm{R}, \mathrm{S}) \leq 0]=\mathrm{P}[\mathrm{R}-\mathrm{S}<0]=\mathrm{P}[\mathrm{Z} \leq 0] \\
& =\int \mathrm{f}_{\mathrm{RS}}(\mathrm{R}, \mathrm{S}) \mathrm{dRdS} \\
& \mathrm{P}[\mathrm{Z} \leq 0]=\mathrm{P}[\mathrm{R}-\mathrm{S}<0] \\
& \mu_{\mathrm{z}}=\mu_{\mathrm{R}}-\mu_{\mathrm{S}}, \sigma_{\mathrm{z}}^{2}=\sigma_{\mathrm{R}}^{2}-\sigma_{\mathrm{S}}^{2}
\end{aligned}
$$

where the $G(r, s)$ is a limit function, $f_{R S}$ is a joint density distribution of load and resistance ( $R$ is resistance and $S$ is stress-load). Mean and standard deviation are marked as $\mu$ and $\sigma$.

S.J. Avinash, M. Tech, Structural Engineering, SIT, Tumkur. E-mail:avinash.april@gmail.com

Dr.J.K. Dattatreya, Research Professor, SIT, Tumkur.

Dr.V. Devaraj, Professor, UVCE, Bangalore.

DOI:10.9756/BIJMMI.8152

\section{FORMULATION OF STEEL BEAM AND COLUMN}

Strength formulation of steel Beam:

$$
\mathrm{G}(\mathrm{R}, \mathrm{S})=\mathrm{R}-\mathrm{S}=\mathrm{F}_{\mathrm{y}} \mathrm{Z}_{\mathrm{e}}-\mathrm{M}
$$

Where $G(R, S)$ is limit function, $F_{y}=$ Yield stress of steel in $\mathrm{N} / \mathrm{mm}^{2}, \mathrm{Z}_{\mathrm{e}}=$ Sectional modulus in $\mathrm{mm}^{3}, \mathrm{M}=$ Moment in $\mathrm{N}-\mathrm{mm}$

Force formulation of column in buckling:

$$
\mathrm{G}(\mathrm{R}, \mathrm{S})=\mathrm{R}-\mathrm{S}=\mathrm{P}_{\mathrm{cr}}-\mathrm{P}
$$

Where

(Critical load) $\mathrm{P}_{\mathrm{cr}}=\Pi^{2} \mathrm{EI} / \mathrm{kL}^{2}$

$\mathrm{P}=$ Actual load(external) in $\mathrm{N}$,

$\mathrm{E}=$ Young's modulus in $\mathrm{N} / \mathrm{mm}^{2}$,

$\mathrm{I}=$ Moment of inertia in $\mathrm{mm}^{4}$,

$\mathrm{L}=$ Length of column in $\mathrm{mm}$,

$\mathrm{k}=$ Effective length factor

\section{A. Hasofer Lind Method}

The Hasofer-Lind method is applicable for normal random variables. It first defines the reduced variables as

$$
X_{i}^{\prime}=\frac{X_{i}-\mu_{X i}}{\sigma_{X i}}(i=1,2, . . n)(8)
$$

Where, $X_{i}^{\prime}$ is a random variable with zero mean and unit standard deviation. Equation 8is used to transform the original limit state $g(X)=0$ to the reduced limit state,

$\mathrm{g}\left(X^{\prime}\right)=0$. The $\mathrm{X}$ coordinate system is referred to as the original coordinate system. The $X^{\prime}$ coordinate system is referred to as the transformed or reduced coordinate system. The safety index, $\beta$ is defined as the minimum distance from the origin of the axes in the reduced coordinate system to the limit state surface (failure surface). It can be expressed as

$$
\beta=\sqrt{\left(X^{\prime *}\right)^{\prime}\left(X^{\prime *}\right)}
$$

The minimum distance point on the limit state surface is called the design point or checking point. It is denoted by vector $\mathrm{X}^{*}$ in the original coordinate system and by vector $\mathrm{X}^{\prime *}$ in the reduced coordinate system. These vectors represent the values of all the random variables, that is, $\mathrm{X} 1, \mathrm{X} 2 \ldots \mathrm{Xn}$ at the design point corresponding to the coordinate system being used.

This method can be explained with the help of Fig 1. Consider the linear limit state equation in two variables,

$$
Z=R-S=0
$$


Note that $\mathrm{R}$ and $\mathrm{S}$ need not be normal variables. A set of reduced variables is introduced as

$$
R^{\prime}=\frac{R-\mu_{R}}{\sigma_{R}}
$$

$$
S=\frac{S-\mu_{S}}{\sigma_{S}}
$$

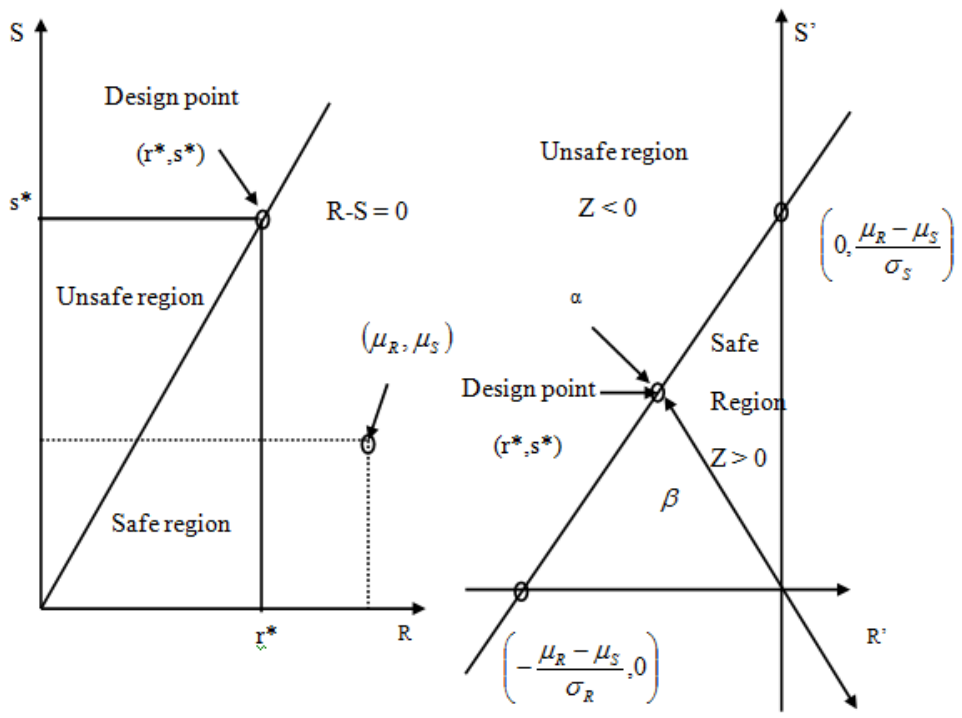

$\begin{array}{ll}\text { (a) Original Coordinates } & \text { (b) Reduced Coordinates }\end{array}$

Figure 1: Hasofer-Lind reliability index: Linear Performance Function

If we substitute these into Equation 10, the limit state equation in the reduced coordinate system becomes

$$
g\left(X^{\prime}\right)=\sigma_{R} R-\sigma_{S} S^{\prime}+\mu_{R}-\mu_{S}=0(13)
$$

The transformation of the limit state equation from the original to the reduced coordinate system is shown in Fig.1b. The safe and failure regions are also shown. From Fig.1b it is apparent that if the failure line (limit state line) is closer to the origin in the reduced coordinate system, the failure region is larger, and if it is farther away from the origin, the failure region is smaller. Thus, the position of the limit state surface relative to the origin in the reduced coordinate system is a measure of the reliability of the system. The coordinates of the intercepts of Equation 13 on the R' and S' axes can be shown to be $\left[-\left(\mu_{R}-\mu_{S}\right) / \sigma_{R}, 0\right]$ and $\left[0,\left(\mu_{R}-\mu_{S}\right) / \sigma_{S}\right]$, respectively.

Using simple trigonometry, we can calculate the distance of the limit state line (Equation 13) from the origin as

$$
\beta=\frac{\mu_{R}-\mu_{S}}{\sqrt{\sigma_{R}^{2}+\sigma^{2} S}}
$$

An algorithm was formulated by Rackwitz (1976) to compute $\beta$ and xi" as follows:

Step 1: Define the appropriate limit state equation.

Step 2: Assume initial values of the design point $x_{i}{ }^{*}, i=1$, $2, \ldots$, n. Typically, the initial design point may be assumed to be at the mean values of the random variables. Obtain the reduced $x_{i}^{* *}=\frac{\left(x_{i}^{*}-\mu_{x i}\right)}{\sigma_{x i}}$.
Step 3: Evaluate $\left(\frac{\partial g}{\partial X_{i}^{\prime}}\right)^{*}$ and $\alpha_{\mathrm{i}}$ at $\mathrm{x}_{\mathrm{i}}$ ".

Step 4: Obtain the new design point $\mathrm{x}_{\mathrm{i}}$ " in terms of $\beta$, as in Equation 14.

Step 5: Substitute the new $\mathrm{x}_{\mathrm{i}}$ " in the limit state equation $\mathrm{g}$ $\left(\mathrm{x}_{\mathrm{i}}{ }^{\prime \prime}\right)=0$ and solve for $\beta$.

Step 6: Using the $\beta$ value obtained in Step 5, evaluate $\beta_{\mathrm{HL}}$ $\mathrm{x}_{\mathrm{i}}{ }^{\prime \prime}=-\alpha_{\mathrm{i}} \beta$.

Step 7: Repeat steps 3 through 6 until $\beta$ converges.

\section{B. System Reliability}

There are basically two types of systems:

\section{Series System}

A system in which all components must be operating for the system to be successful is called a series system. Alternatively, the failure of any one component will cause the system to fail. The reliability of a series system is the probability that all the components in the system are successful. For $\mathrm{n}$ independent components, this is:

$$
\mathrm{R}=\prod_{1}^{\mathrm{n}}(1-\mathrm{p})
$$

Where $\mathrm{p}$ is probability of failure of individual components. 


\section{Parallel System}

A system for which the success of any one component is equivalent to the success of the system is a parallel system. Alternatively, all the components must fail before the parallel system fails. The reliability of a parallel system is the probability that all of the components do not fail. Assuming independence, we have

$$
\mathrm{R}=1-\prod_{1}^{\mathrm{n}}(\mathrm{p})
$$

Where $p$ is probability of failure of individual components.

\section{PROBLEM}

Calculate the reliability index and sensitivity of variables of the components for a structure given in the figure below. Also find the system reliability of the structure.

Data:Dead load $=11.25 \mathrm{kN}$,

Live load $=12 \mathrm{kN}$, Super imposed dead load $=4.5 \mathrm{kN}$, $\mathrm{H} 1=2.72 \mathrm{kN}$ (First floor)

$\mathrm{H} 2=10.86 \mathrm{kN}$ (Second floor)

$\mathrm{H} 3=24.46 \mathrm{kN}$ (Third floor)

$\mathrm{H} 4=42.02 \mathrm{kN}$ (Fourth floor)

$\mathrm{Fy}=250 \mathrm{~N} / \mathrm{sq} \cdot \mathrm{mm}, \mathrm{E}=200000 \mathrm{~N} / \mathrm{sq} \cdot \mathrm{mm}$

Earthquake Zone V, Load combination: 1.2(DL+LL+ SIDL+EQX)

Special Moment Resisting Frame

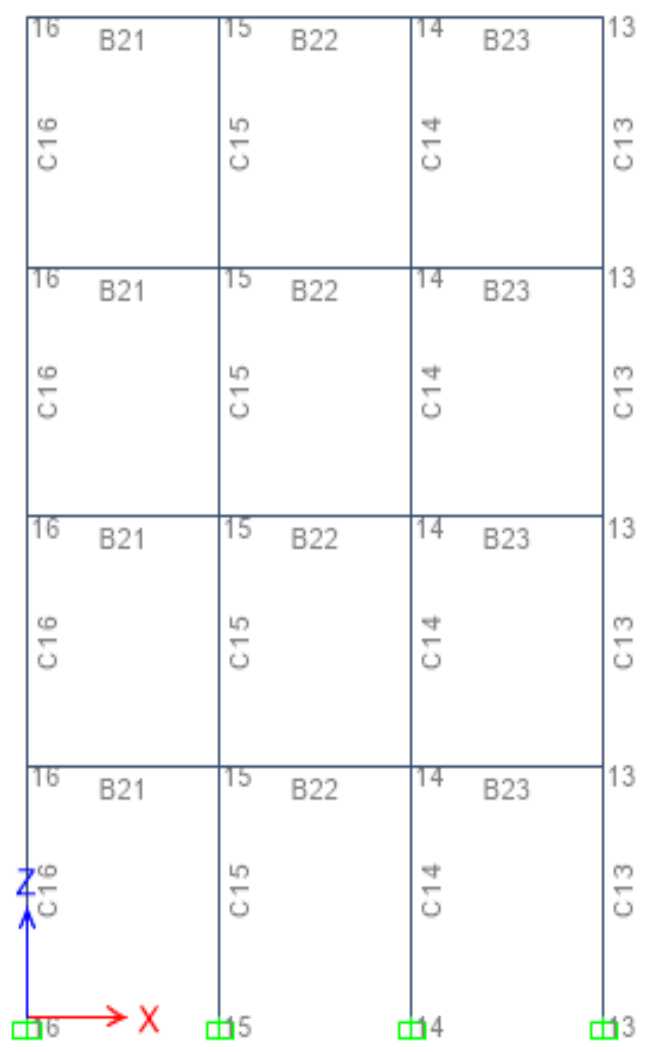

Figure 2: Model of the Structure

\section{Elastic Analysis Results}

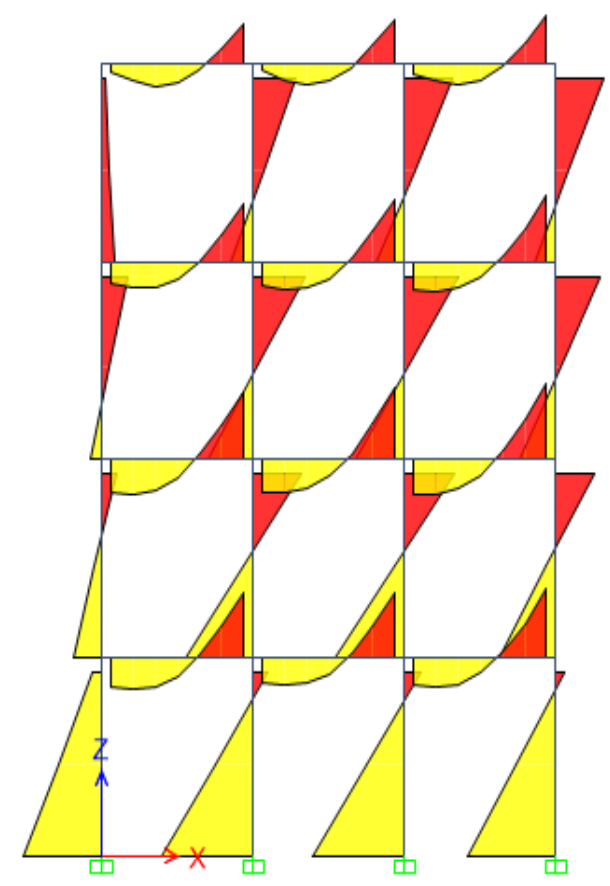

Figure 3: Bending Moment Diagram

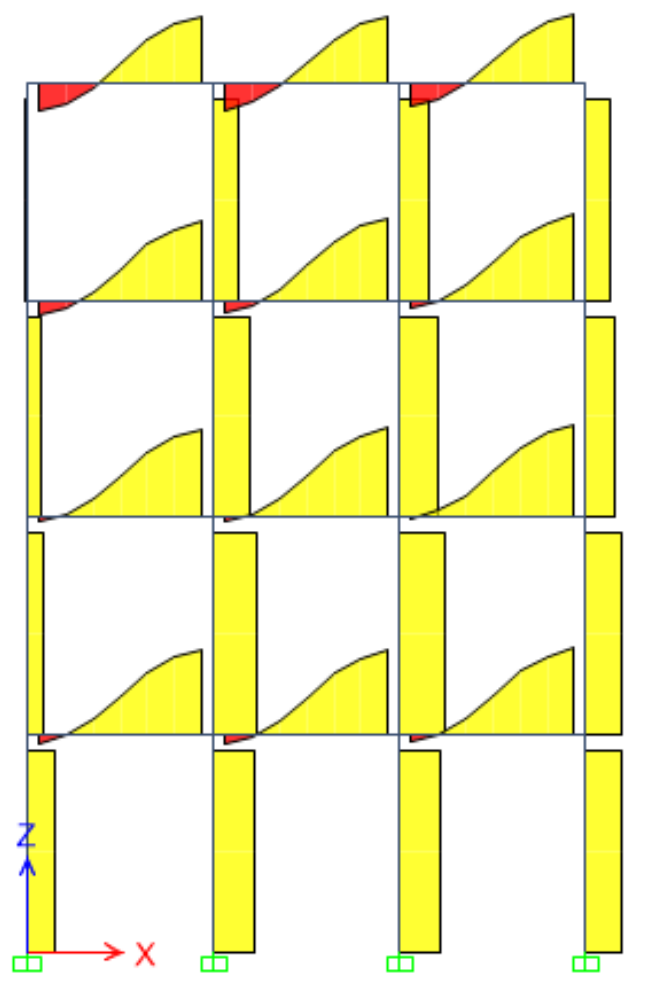

Figure 4: Shear Force Diagram 


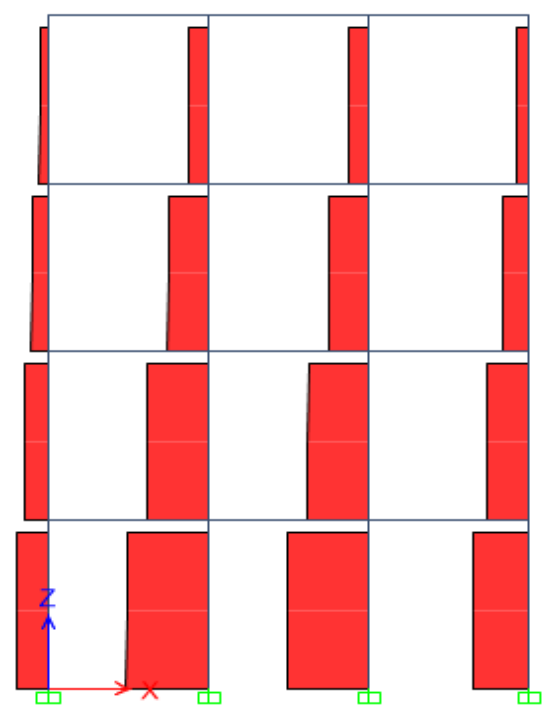

Figure 5: Axial Loads on Columns

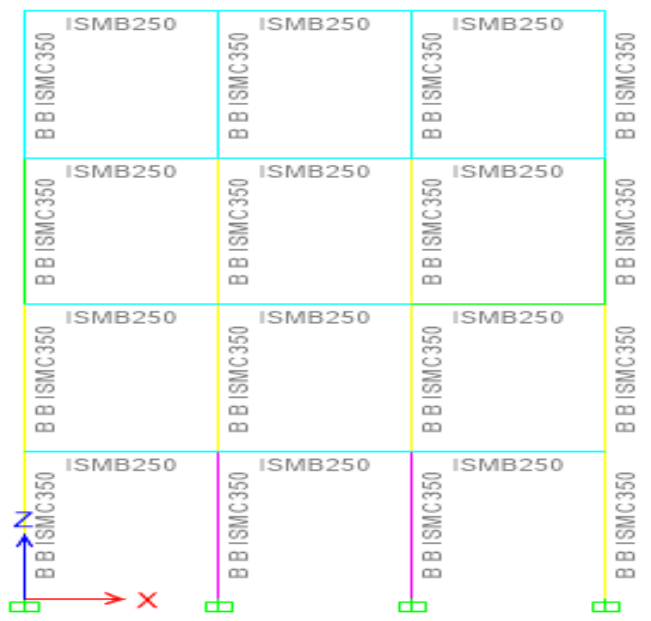

Figure 6: Steel Sections for Beam and Column

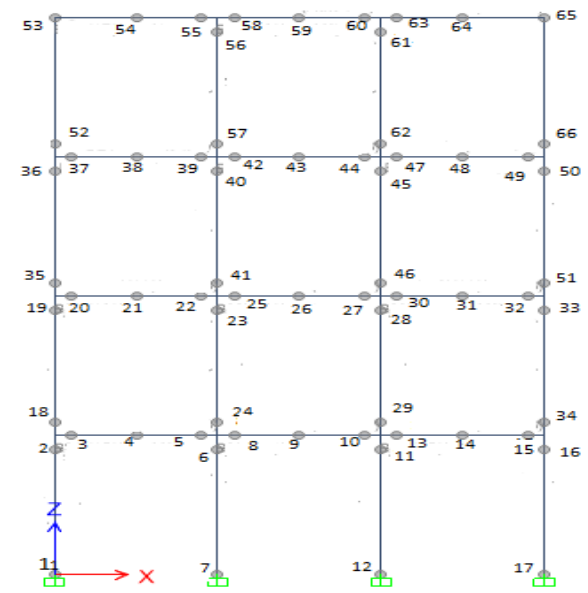

Figure 7: Expected Hinge Location

\section{A. Statistical Data of Random Variable}

Table 1: Statistical Data of Random Resistance and Geometrical Variables

\begin{tabular}{|l|l|l|}
\hline Variable & Mean & Standard Deviation \\
\hline $\mathrm{Z}\left(\mathrm{mm}^{3}\right)$ & 447290 & 0.05 \\
\hline $\mathrm{F}_{\mathrm{y}}\left(\mathrm{N} / \mathrm{mm}^{2}\right)$ & 272.405 & 0.05 \\
\hline $\mathrm{L}($ column $)(\mathrm{mm})$ & 3813.674 & 0.05 \\
\hline $\mathrm{E}\left(\mathrm{N} / \mathrm{mm}^{2}\right)$ & $2.179 \times 10^{5}$ & 0.05 \\
\hline $\mathrm{A}($ column $)\left(\mathrm{mm}^{2}\right)$ & 17151 & 0.05 \\
\hline $\mathrm{r}_{\min }($ column $)$ & 37.7 & 0.05 \\
\hline
\end{tabular}

Table 2: Statistical Data of Load Variable

\begin{tabular}{|c|c|c|c|c|}
\hline $\begin{array}{l}\text { Floor } \\
\text { No. }\end{array}$ & $\begin{array}{l}\text { Mean Bending } \\
\text { Moment }(k N m)\end{array}$ & $\begin{array}{l}\text { Mean Shear } \\
\text { force }(k N)\end{array}$ & $\begin{array}{l}\text { Mean Axial } \\
\text { force }(k N)\end{array}$ & $\begin{array}{l}\text { Standard } \\
\text { deviation }\end{array}$ \\
\hline 1 & $\begin{array}{l}\mathrm{B} 21=28.44 \\
\mathrm{~B} 22=28.61 \\
\mathrm{~B} 23=30.14\end{array}$ & $\begin{array}{l}\mathrm{B} 21=34.57 \\
\mathrm{~B} 22=34.07 \\
\mathrm{~B} 23=35.01\end{array}$ & $\begin{array}{l}\mathrm{C} 13=263.74 \\
\mathrm{C} 14=382.73 \\
\mathrm{C} 15=386.23 \\
\mathrm{C} 16=149.85\end{array}$ & 0.2 \\
\hline 2 & $\begin{array}{l}\mathrm{B} 21=30.40 \\
\mathrm{~B} 22=34.54 \\
\mathrm{~B} 23=33.76\end{array}$ & $\begin{array}{l}\mathrm{B} 21=36.02 \\
\mathrm{~B} 22=36.31 \\
\mathrm{~B} 23=37.70\end{array}$ & $\begin{array}{l}\mathrm{C} 13=196.60 \\
\mathrm{C} 14=286.48 \\
\mathrm{C} 15=288.53 \\
\mathrm{C} 16=114.35\end{array}$ & 0.2 \\
\hline 3 & $\begin{array}{l}\mathrm{B} 21=25.35 \\
\mathrm{~B} 22=27.49 \\
\mathrm{~B} 23=29.77\end{array}$ & $\begin{array}{l}\mathrm{B} 21=32.02 \\
\mathrm{~B} 22=33.27 \\
\mathrm{~B} 23=34.75\end{array}$ & $\begin{array}{l}\mathrm{C} 13=122.69 \\
\mathrm{C} 14=191.47 \\
\mathrm{C} 15=192.42 \\
\mathrm{C} 16=80.73\end{array}$ & 0.2 \\
\hline 4 & $\begin{array}{l}\mathrm{B} 21=18.31 \\
\mathrm{~B} 22=19.72 \\
\mathrm{~B} 23=21.15\end{array}$ & $\begin{array}{l}\mathrm{B} 21=27.17 \\
\mathrm{~B} 22=27.45 \\
\mathrm{~B} 23=28.46\end{array}$ & $\begin{array}{l}\mathrm{C} 13=60.98 \\
\mathrm{C} 14=96.99 \\
\mathrm{C} 15=97.71 \\
\mathrm{C} 16=43.33\end{array}$ & 0.2 \\
\hline
\end{tabular}

\section{B. Reliability Analysis results}

Reliability analysis of Steel Beam

Table 3: Tabulation of Reliability Index and Direction Cosine of Beam

\begin{tabular}{|l|l|l|l|l|l|}
\hline Floor no. & Beam no. & $\beta$ & $\alpha_{1}$ & $\alpha_{2}$ & $\alpha_{3}$ \\
\hline 1 & B21 & 9.96 & -0.52 & -0.52 & 0.66 \\
& B22 & 9.91 & -0.52 & -0.52 & 0.66 \\
& B23 & 9.51 & -0.51 & -0.51 & 0.68 \\
\hline 2 & B21 & 9.44 & -0.51 & -0.51 & 0.68 \\
& B22 & 9.15 & -0.51 & -0.51 & 0.69 \\
& B23 & 8.62 & -0.50 & -0.50 & 0.7 \\
\hline 3 & B21 & 10.85 & -0.54 & -0.54 & 0.64 \\
& B22 & 10.22 & -0.53 & -0.53 & 0.65 \\
& B23 & 9.60 & -0.51 & -0.51 & 0.67 \\
\hline 4 & B21 & 13.26 & -0.58 & -0.58 & 0.56 \\
& B22 & 12.73 & -0.57 & -0.57 & 0.58 \\
& B23 & 12.21 & -0.56 & -0.56 & 0.6 \\
\hline
\end{tabular}

Table 4: Sensitivity of Beam Variables

\begin{tabular}{|l|l|l|l|l|}
\hline Floor no. & Beam nos. & $Z_{e}(\%)$ & $F_{v}(\%)$ & $M(\%)$ \\
\hline \multirow{4}{*}{1} & B21 & 28 & 28 & 44 \\
& B22 & 28 & 28 & 44 \\
& B23 & 27 & 27 & 46 \\
\hline \multirow{3}{*}{2} & B21 & 26 & 26 & 48 \\
& B22 & 26 & 26 & 48 \\
& B23 & 25 & 25 & 50 \\
\hline \multirow{3}{*}{3} & B21 & 29 & 29 & 42 \\
& B22 & 28 & 28 & 44 \\
& B23 & 27 & 27 & 46 \\
\hline \multirow{4}{*}{4} & B21 & 33 & 33 & 34 \\
& B22 & 32 & 32 & 36 \\
& B23 & 31 & 31 & 38 \\
\hline
\end{tabular}




\section{Reliability analysis of Steel Column}

Table 5: Tabulation of Reliability Index and Direction Cosine of Column

\begin{tabular}{|l|l|l|l|l|l|l|l|}
\hline Floor no. & Column nos. & $\beta$ & $\alpha_{1}$ & $\alpha_{2}$ & $\alpha_{3}$ & $\alpha_{4}$ & $\alpha_{5}$ \\
\hline \multirow{4}{*}{1} & C13 & 11.98 & -0.24 & -0.24 & -0.76 & 0.34 & 0.41 \\
& C14 & 10.36 & -0.26 & -0.26 & -0.71 & 0.37 & 0.46 \\
& C15 & 10.32 & -0.26 & -0.26 & -0.71 & 0.37 & 0.46 \\
& C16 & 14.12 & -0.19 & -0.19 & -0.85 & 0.28 & 0.34 \\
\hline \multirow{5}{*}{3} & C13 & 13.14 & -0.22 & -0.22 & -0.81 & 0.31 & 0.37 \\
& C14 & 11.63 & -0.24 & -0.24 & -0.75 & 0.35 & 0.42 \\
& C15 & 11.60 & -0.24 & -0.24 & -0.75 & 0.35 & 0.42 \\
& C16 & 14.98 & -0.17 & -0.17 & -0.88 & 0.25 & 0.30 \\
\hline \multirow{5}{*}{4} & C13 & 14.66 & -0.18 & -0.18 & -0.87 & 0.26 & 0.32 \\
& C14 & 13.24 & -0.21 & -0.21 & -0.81 & 0.31 & 0.37 \\
& C15 & 13.23 & -0.21 & -0.21 & -0.81 & 0.31 & 0.37 \\
& C16 & 15.91 & -0.13 & -0.13 & -0.92 & 0.20 & 0.26 \\
\hline & C13 & 16.50 & -0.11 & -0.11 & -0.94 & 0.17 & 0.22 \\
& C14 & 15.44 & -0.15 & -0.15 & -0.90 & 0.23 & 0.28 \\
& C15 & 15.42 & -0.15 & -0.15 & -0.90 & 0.23 & 0.28 \\
& C16 & 17.06 & -0.09 & -0.09 & -0.96 & 0.13 & 0.18 \\
\hline
\end{tabular}

Table 6: Sensitivity of Column Variables

\begin{tabular}{|l|l|l|l|l|l|l|}
\hline Floor & Column nos. & $E(\%)$ & $A(\%)$ & $r_{\min }(\%)$ & $L(\%)$ & $P(\%)$ \\
\hline 1 & C13 & 5.76 & 5.76 & 57.76 & 11.56 & 16.81 \\
& C14 & 6.76 & 6.76 & 50.41 & 13.69 & 21.16 \\
& C15 & 6.76 & 6.76 & 50.41 & 13.69 & 21.16 \\
& C16 & 3.88 & 3.88 & 72.25 & 7.84 & 11.56 \\
\hline 2 & C13 & 4.84 & 4.84 & 65.61 & 9.61 & 13.69 \\
& C14 & 5.76 & 5.76 & 56.25 & 12.25 & 17.64 \\
& C15 & 5.76 & 5.76 & 56.25 & 12.25 & 17.64 \\
& C16 & 2.89 & 2.89 & 77.44 & 6.25 & 9.00 \\
\hline 3 & C13 & 3.20 & 3.20 & 75.69 & 6.76 & 10.24 \\
& C14 & 4.41 & 4.41 & 65.61 & 9.61 & 13.69 \\
& C15 & 4.41 & 4.41 & 65.61 & 9.61 & 13.69 \\
& C16 & 1.69 & 1.69 & 84.64 & 4.00 & 6.76 \\
\hline 4 & C13 & 1.21 & 1.21 & 88.36 & 2.89 & 4.84 \\
& C14 & 2.25 & 2.25 & 81.00 & 5.29 & 7.84 \\
& C15 & 2.25 & 2.25 & 81.00 & 5.29 & 7.84 \\
& C16 & 0.81 & 0.81 & 92.16 & 1.69 & 3.24 \\
\hline
\end{tabular}

\section{System Reliability Results}

Twenty seven failure modes has been identified and reliability index was calculated for each mode. To get the worst probability of failure, the system was considered as a series system. Therefore Reliability of the system is:

$$
\mathrm{R}=\prod_{1}^{27}(1-0.00001)=0.99973
$$

Probability of failure of the system:

$$
\mathrm{Pf}=1-0.99973=0.00027
$$

\section{Load and Resistance Factor}

Load and resistance factors are given by:

$$
\text { Resistance factor }\left({ }^{\Phi}\right)=\exp (\alpha \mathrm{R} * \beta(\operatorname{cov}) \mathrm{R})
$$

\section{Load factor $(\gamma)=\exp \left(\alpha S^{*} \beta(\operatorname{cov}) S\right)$}

Where $(\operatorname{cov}) \mathrm{R}=$ Covariance of Resistance,

$(\operatorname{cov}) \mathrm{S}=$ Covariance of strength, $\beta=$ Reliability index

Average load factor for beam $=3.87$

Average resistance factor for beam $=0.57$

Average load factor for column $=2.47$

Average resistance factor for column $=0.17$
Table 7: Load and Resistance Factor for Beam

\begin{tabular}{|l|l|l|l|}
\hline Floor no. & Beam nos. & Load factor $(\gamma)$ & Resistance factor $\left({ }^{(}\right)$ \\
\hline \multirow{3}{*}{1} & B21 & 3.78 & 0.59 \\
& B22 & 3.76 & 0.59 \\
& B23 & 3.65 & 0.61 \\
\hline \multirow{3}{*}{3} & B21 & 3.63 & 0.61 \\
& B22 & 3.54 & 0.62 \\
& B23 & 3.38 & 0.64 \\
\hline \multirow{4}{*}{4} & B21 & 4.01 & 0.55 \\
& B22 & 3.85 & 0.58 \\
& B23 & 3.67 & 0.60 \\
\hline & B21 & 4.52 & 0.46 \\
& B22 & 4.43 & 0.48 \\
\hline
\end{tabular}

Table 8: Load and Resistance Factor for Column

\begin{tabular}{|l|l|l|l|}
\hline Floor & Column nos. & Load factor $(\gamma)$ & Resistance factor $\left({ }^{\varphi}\right)$ \\
\hline \multirow{4}{*}{1} & C13 & 2.67 & 0.20 \\
& C14 & 2.59 & 0.24 \\
& C15 & 2.59 & 0.24 \\
& C16 & 2.61 & 0.15 \\
\hline \multirow{4}{*}{2} & C13 & 2.64 & 0.17 \\
& C14 & 2.65 & 0.21 \\
& C15 & 2.65 & 0.21 \\
& C16 & 2.45 & 0.14 \\
\hline \multirow{4}{*}{3} & C13 & 2.55 & 0.14 \\
& C14 & 2.66 & 0.17 \\
& C15 & 2.66 & 0.17 \\
& C16 & 2.28 & 0.13 \\
\hline \multirow{4}{*}{4} & C13 & 2.06 & 0.13 \\
& C14 & 2.37 & 0.13 \\
& C15 & 2.37 & 0.13 \\
\hline
\end{tabular}

\section{CONCLUSION}

1. The beam and column components designed according to IS 800:2007 are safe but uneconomical as target reliability index according to ISO is 3.5 .

2. All the identified failure modes are safe $(\beta>3.5)$.

3. Beams are more sensitive to loads and columns are sensitive to radius of gyration.

4. The bounds of system reliability ranges from $0<\mathrm{p}_{\mathrm{f}}<0.00027$.

5. The load factors are greater than unity and resistance factors are less than unity.

6. LRFD form:

For beam $\quad 0.57 \mathrm{R} \geq 3.87 \mathrm{~S}$

For column $\quad 0.17 \mathrm{R} \geq 2.47 \mathrm{~S}$

\section{REFERENCES}

[1]. Palle Thoft Christensen and Michael.J.Baker, "Structural reliability theory and its applications", Springer-Verlag Berlin Heidelberg, New York 1982

[2]. R. Ranganathan. "Structural reliability analysis and design", Jaico publishing house, India, 1999.

[3]. Andre T. Beck and Andre S. Doria, "Reliability analysis of I-section steel columns designed according to new Brazilian building codes", Journal of Brazil society of Mech. Sci.\&Eng., Vol.XXX, No.2, Pp.152159, Brazil, 2008.

[4]. S.D.Bhatnagar, V.K.Sehgal and Krishan Gopal, "Computational technique for reliability analysis and design of steel beam", International journal of information technology and knowledge management, page.511-513 India, 2010.

[5]. Devaraj.V., "Reliability analysis and design for civil engineers", I.K. Publishers, India, to be published in 2016.

[6]. P.Thoft-christensen and J.Dalsgard Sorensen, "Reliability of structural systems with correlated elements", appl. Math. Modelling, Vol.6, Pp.171-178, Denmark 1982. 